\title{
大地构造学的哲学問題*
}

陈国达

大地构造学是一門高度綜合性和理諭性 的科学。它往往涉及地稹科学中的一些带根 本性的問題, 因而与哲学問題具有特別密切 的关系，而尤以表現在关于地壳发展規律問 題上, 最为明显。由于地壳发展規律問題既 是大地构造学的基本問題，又是涉及其他各 門有关的地盾科学以及一些有关的边緣科学 的基础理論問題。因此, 大地构造学的哲学 問題, 同时也是有关的各門地稹科学和边緣 科学的哲学間題的基础。

近年来，作者在总結历年有关的研究成 果的基础上, 以地壳发展規律間題为中心， 对大地构造学的哲学問題进行了点滴的研 究。茹将个人初步体会, 分为下列几个問題 写出来, 以供大家研究这一問題时的参考。 这几个問題是互相联系、互相渗透、不可分 割的。下交依次諭述，只是为了便利而已。

\section{一 地孛不斷发展与发展阶段問題}

\section{（一）地壳发展的不断前进性}

关于地壳发展史的看法，大致可以归納 为两大类: 第一类看法, 主张地壳的基本构 造单元仅有两个, 郎地槽区和地台区, 并訩
为前者是唯一的活动区，后者是唯一的“稳 定”区。其中及可分为三种見解：第一种見 解訩为, 地壳的起点就是地槽区, 終点就是地 台区, 如地槽一地台說 (地台扩大說、泛地槽 說) 属之。第二种見解䚿为, 地壳发展是先 有地台区，其后才出現地槽区，如地台一地槽 說(地台崩潰說、泛地台說)郎是这样。第三 种見解則䚯为，地槽区和地台区是反复出現 的, 如槽台可逆循环說 (多輪迴說)是。至于 第二类看法, 則主张地壳发展是不断前进 的，是多构造单元的。无論在地槽区形成之 前，抑或継在地台区之后，都还有其他构造 单元出現，其中既有活动区，也有“稳定” 区; 无論活动区抑“稳定”区都不止前此所知 的一种。这是近年来所出現的一类看法。地 壳动定轉化递进說的主张, 郎属如此。

1. 地壳构造是多單元的生产实践的 經驗証明，地壳构造发展的基本形式銿不是 仅仅过去所䚯識的地槽区和地台区两个。无 論“地槽一地台說”，抑或“地台一地槽說”。

* 本交曾先后于 1961 年 5 月 31 日在长沙中南信台学 院大地构海討論会上、1962 年 12 月在北（中国地

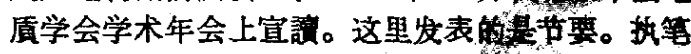

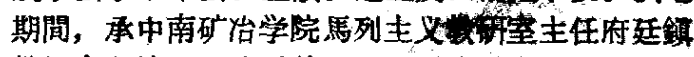
教授多所协助。在討論会上以及会后各有关单位村 論时, 又承許多同志提福宣意胃，得以改正和补 充, 謹此致謝! 
只是看到地壳中許多基本构造单元中的两个 校早受到注意者而已。一方面由于地洼活动 的研究，闈明了継地台区之后还有地洼区这 个新构造单元的出現; 而且, 考虑到地洼区 发展的前途，可以預測，継其后可能还会有 其他更新的构造单元 (例如 $Y_{1}$ 等) 形成。另 一方面，由于先震旦紀地壳发展史的研究， 又已陆䌮发見了一些在地槽区形成之前已存 在过的古老构造单元，例如 $\mathrm{X}_{-1}$ (地原区)、 $\mathrm{X}_{-2}$ (地盆区)、 $\mathrm{X}_{-n}$ (原始构造区) 等。这 些已知的和預測的几个构造单元，按其历史 生因順序来排队，就是：原始构造区 $\left(\mathrm{X}_{-n}\right) 、 \cdots$ 地盆区 $\left(\mathrm{X}_{-2}\right)$ 、地原区 $\left(\mathrm{X}_{-1}\right)$ 、地 槽区、地台区、地洼区、 $Y_{1} \cdots$ [1]。 $^{[1]}$

2. 活动区与“稃定”区是多类型的上 述各个已知的基本构造单元，依它們的性稹 来說，可以归納为两大类: 一为活动区，如 地盆区、地槽区、地洼区等属之; 一为“稳 定”区，如原始构造区、地原区、地台区等 是。据此得知，地壳中无諭活动区抑“稳定” 区都不止一种。也就是説，在地壳的发展史 中，无論活动区抑“稳定”区，它們中的任何 一类，都曾不止一次地出現过。而且，其中 較新的活动区与較老的活动区之間，以及較 新的“稳定”区与較老的“稳定”区之間，都是 既有联系，也有区別，既有相似，但又不全相 同，而不能混为一談的。黃汲清[1962]把地 槽区及地台区当作唯一的活动区及唯一的 “稳定”区，把把这两个构造单元看做活动区 “稳定”区的同义語。他䚯为，凡活动区就 一定是而且只能是地槽区，凡“稳定”区就一 定是而且只能是地台区。这显然是不切实际 的。他的垀多錯誤覌点師系由于这个基本概 念上的理解錯詇面来的。
知构造单元的历史生因順序看来，可以得 知，地台区不是单純扩张及稳固不变的， 它和任何事物一样, 也有发生、发展和死亡。 新的資料証明，地台区在一定的地史时期 內，既确在扩大，但也确在崩漬。扩大是它 代替了以前的活动区，即代替了日盖縮小的 地槽区; 崩潰則是它被一个新的、日漸扩展 的构造单元所代替一这是个新的活动区, 地台一地槽說䚯为它就是地槽区; 但其特征 指明，它实际上是与地槽区有別的地洼区。 因此，在这一点上，无論“地台扩大說”抑 或“地台崩溃説” 都是有一定根据的，但都 不全面，而只看到事实的一面。

其次, 上举的事实又愦明, 无論地槽区 抑地台区, 都不是地壳发展的最初形式; 地 壳从一开始就已有了大地构造单元的分异, 而且陆續演化为以后的各种构造单元。故在 地槽区和地台区出現之前，已經有过若干个 其他基本构造单元存在过。其中一部分为 “稳定”区，另一部分为活动区一一地槽一地 台說以为这些古老的活动区就是地槽区，而 地台一地槽說則以为这些古老的“稳定”区就 是地台区。然二說都似乎没有注意到这些构 造单元在特征上与真正的地槽区或真正的地 台区之間具有明显的差別的事实。所以，对

[1] 这些构造单元中，地洼区是与地槽区相似但又有別 的新型活动区，已詳見专书 $[1960 ，$ 陈]。Y是由地 注区“稳定”化而成的新型“稳定”区，預測已經发生， 但份待发見。地盆区及地原区二者分別以結晶基底 深变盾岩系中的袺酸強烈部分和少受变动部分为代 表, 前者是与地梅区相似但又有別的古型活动区, 后 者是与地台区相隹但又有别的古型“稳定”区。原始 构遗区即原始地壳，由象太平洋中部那样的矽鎂构 造层为代表，它是可能最早出現的私造单元，屈于 “稳定”区。关于这几个古型构造单元，已見另文 [1961]。因䈐楅所限，又非本交范围; 这里不作䌅 达。又,由于原始构造区与地盆区或地原区之間,究 晦还有多少个构浩单元存在过, 目前佮在探究中, 故 整用点綫来表示这一法陆，留待将来发見。 
于地壳发展的起初情况来說，无論“泛地槽 群”抑或“泛地台說”，都是值得商榷的。

由此可見，地壳是在不断地向前发展 的。它的任何一部分, 其大地构造性稹都不 是一成不变的。'这正反映着事物在不断运 动、变化和发展着的客覌規律。很难設想, 在长达 35 亿年以上的漫长的地壳发展史中， 除了地槽区和地台区外，沒有其他构造单元 出現过。还有那种訩为槽台永世释存、与地 球同始終，以及䚯为地台区的发展只能是所 謂可逆再生、重成地槽区，而不可能向前发 展、递进轉化为其他类型的构造单元的多輪 迴覌点 [1962，黃]，也是不符合实际的。它 和缺之发展观点的均变諭覌点是相一致的。 正如 H. K. 尼古拉耶夫 [1954，尼] 所指出 的一样:“把地稹历史中地壳构造发展的多样 性仅仅归結为两个現在采納的单元”“作为唯 一的最主要的地壳构造单元, 这种說法, 在 方法論上是不正确的”。它“規定了地槽区和 地台区在时間上的永恆性，而沟考虑到这些 构造单元的新的性貭和新的貭量的增长，以 及他們向新的、我們还沒有划分出来的构

) 造形态的轉化”。

\section{（二）地壳发展的多阶段性}

目前，有关地壳发展阶段問題，有两类 不同的薏見：一类意兒䚿为，地壳发展史只 有两个基本阶段，另一类意自則訩为，地壳 发展阶段是多个的。在主张多阶段的学說 中,文可分为两种看法: 有些人訩为, 这些阶 段只是由于地槽区与地台区这二个特定的构 造单元的可逆循环、交替重复出現而表現出 来的。另一些人則䚯为, 不同的发展阶段有 着不同的大地构造性稹，这些阶段是由于不 同性稹、不同类型的构造单元 (各种不同的
活动区和各种不同的稳定区）的陆續出現而 形成的。

主张第一类意見的，是地槽一地台説。此 外，地台一地槽說的本来論点，也属此类。但 在地台一地槽論者中，有些人由于看到了地 壳发展过程实际上是比較复杂的, 逐把它由 “泛地台一地槽”改为“泛地槽 一泛地台 一地槽”。这表明，他們䚯为地壳发展过 程是由于地槽区和地台区的交替重复而显出 多阶段性的。那些訩为地台区可以普遍地并 且必然和只能再生重成地槽区的多輪䢙論 者, 更是主张由于槽台可逆循环因而形成多 阶段性者的典型代表。

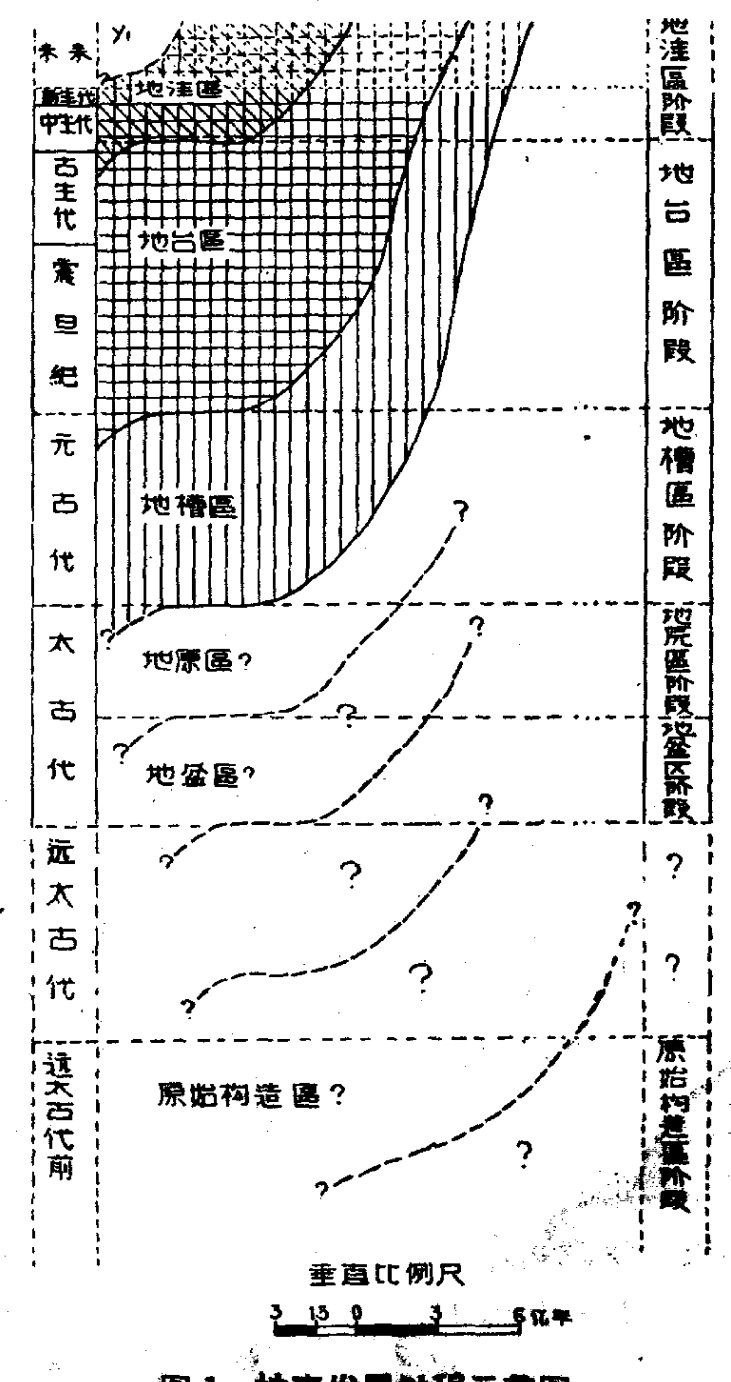

图 1 地完发展过程示意国 
至于圭张地壳发展是多构造单元、多阶 段的，則可以动定轉化递进說为代表。

\section{1. 地壳發展是多階段的根据上文所} 列事实，地壳发展史是多阶段的。而且，这 种多阶段性，是由于各种不同的活动区和各 种不同的“稳定”区相継出現而形成的。就現 有凟料看来，地壳发展的总的过程 (不是每 个地区皆如此)，至少可以划分为六个基本 阶段（图 1)。这些已知的基本阶段中，就地
壳的总的情况（不是每个地区每个时期皆全 属此情况）来說，活动区阶段和“稳定”区阶 段是交替出現的。每一基本阶段都是以相应 的一种基本构造单元在地球上的总面积逐濑 地但显著地扩展为主要特征的, 但与此同 时，还可以有代表以前各个阶段的各种构造 单元殘留、成长或新生，而在它的后期又往 往已开始出現了代表次一阶段的較新的构造 单元。这些阶段有如下列:

\begin{tabular}{|c|c|c|c|c|}
\hline 基本发展阶段 & 地稹时代 & 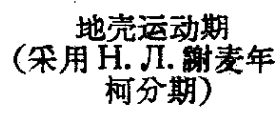 & $\begin{array}{c}\text { 主要特点及代表构遺 } \\
\text { 元 }\end{array}$ & $\begin{array}{c}\text { 代表构造单元的大 } \\
\text { 地构造性盾 }\end{array}$ \\
\hline . & $\cdot$ & $?$ & $?$ & $?$ \\
\hline & $?$ & $?$ & $\mathrm{Y}_{1}$ 区逐步扩展，....... & “稳定”区 \\
\hline 地洼区阶段 & $\begin{array}{c}\text { 中生代-新生代及未来 } \\
\text { 一定的地盾时閻丙 }\end{array}$ & 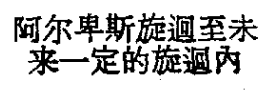 & $\begin{array}{c}\text { 地洼区逐步扩憱 (后； } \\
\text { 期出現 } Y_{1} \text { ， }\end{array}$ & 活 动区 \\
\hline 地台区阶段 & 震旦紀-古生代 & $\begin{array}{c}\text { 貝加尔巨旋洄至海 } \\
\text { 西旋迴 }\end{array}$ & $\begin{array}{c}\text { 地台区逐步搌 (后 } \\
\text { 期出現地洼区) }\end{array}$ & “稳定”区 \\
\hline 地槽区阶段 & 主要属元古代 & 元古巨旅迴 & $\begin{array}{c}\text { 地槽区逐频护展 (后 } \\
\text { 期出垷地台区) }\end{array}$ & 活 动 区 \\
\hline 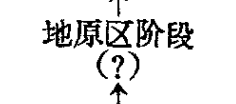 & 可能主要属晚太古代 & 太古巨旋迴晚期 & $\begin{array}{l}\text { 地原区 }\left(\mathrm{X}_{-1}\right) \text { 逐步护 } \\
\text { 展(后期出現地槽区) }\end{array}$ & “稳定”区 \\
\hline $\begin{array}{c}\text { 地萮区阶段 } \\
(?) \\
\text { ? }\end{array}$ & 可能主要属早太古代 & 太古巨旋過早期 & $\begin{array}{l}\text { 地盆区 (X_-2) 逐步护 } \\
\text { 后期出現地原区) }\end{array}$ & 活动区 \\
\hline ! & 可能主要属远太古代 & 远太古巨旋呬 & $?$ & $?$ \\
\hline$\uparrow$ & & & $?$ & $?$ \\
\hline 原始构浩区阶段 & 可能主要属远太古代前 & $?$ & $\begin{array}{c}\text { 原始构造区 }\left(\mathrm{X}_{-n}\right) \text { 在 } \\
\text { 地球发展过程中逐步 } \\
\text { 扩展, …... }\end{array}$ & “稳定”区 \\
\hline
\end{tabular}

2. 地壳發展多階段性的形成原因上 列几个已知的基本阶段，彼此之間具有紧密 的联系，互相过渡，不能截然分割。然而，他 們又各有其自己的特点，郎每一个阶段都以 一个相应的基本构造单元特別发有或迅速扩 展为标志, 而每一个基本构造单元, 又都有自 已的特征。这些特点和特征使得任何一个基 本发展阶段与它的前后各个其他基本发展阶 段之間都互相区別开来。例如，就拿已經研 究得比較詳細的增棈区、地台区及地洼区三
者来說，地槽区是一个活动区，一般地具有 下列的基本特征: 前期多复理式建造、硬砂 岩建造等, 海相为主, 后期出現磨拉斯式建 造; 其沉积物分选性差, 岩性及厚度的稳定性 小，具带状分布特性; 在地槽部分厚度可很 大, 但在地背斜部分, 則常急剧变薄。这些 特征, 反映出当时是一种构造反差強烈、升 降差异运动急剧, 并因此引起地貌反差強烈 的大地构造环境。其次，褶解作用剧烈，同 时还有一般地大体上从基性到酸性一系列复 
杂的強烈的岩浆活动，以及显著的区域变稹 作用等。地台区則是一个“稳定”区，其基本 特征是：沉积建造一般地分选性較好，岩性 及厚度的稳定性較大, 急剧变化現象較少 見, 通常具面状分布特性; 总厚度大小不 一，在台隆部分可以很薄或缺失，但在台陷 部分也可逐淵增至很厚。这些特点, 反映着当 时在大部分地区以大面积的升降运动为主, 差异运动比較和緩，构造起伏及地貌起伏的 反差微弱的大地构造环境。其次,亥被作用、 岩浆活动及变盾作用一般地均較不显著。至 于地洼区，又是一个活动区，其特色 [1960， 陈]是: 沉积物一般地具有华夏式建造(或称 类磨拉斯式建造; 在中国的华夏式建造所包 括的亚建造有萍乡式建造、建德式建造、衡阳 式建造、丹霞式建造等)，陆相为主; 分选 性差，岩性及厚度的稳定性小，急剧变化多 見; 具短带状分布特性; “在地洼部分厚度常 可很大，但在地穹部分則每驟然尖灭。这些 特色，反映当时的大地构造环境也是差异运 动急剧的、具有反差强烈的构造起伏和地貌 起伏的。裮被以宽展型的为多，也有紧閉型

的; 断裂通常十分发育; 岩将活动大多数強 烈而复杂，般地前期以大量酸性、中性 岩为主, 而后期 則以基性岩及磆性岩占优 势; 有时可发生較显著的变盾作用, 尤以 “断裂变稹作用” 为其特色 [1962，莫]。由 此可見, 地壳发展的各个不同阶段之間, 固 然具有密切的联系，不能截然分开，但同时 也具有明显的区別，不能彼此混为一談。这 种阶段性不独从整个地壳的发展过程来看是 十分明显的, 就是从地壳中各个不同部分的 发展过程来說, 也是不可忽略的。又不独在 各个不同的基本发展阶段之間, 其差异是很 大的, 就是在同一基本发展阶段的各个不同
小阶段之間，由于同一基本构造单元的前后 各个时期的发展特点每有較显著的差异, 因 而也有一定的性稹上的区別。这些事实，体 現出地壳发展的过程, 是不断发展与发展阶 段对立統一的过程，連續性与間断性对立統 一的过程。

\section{（三）地壳发展的不平衡性和多样性}

地壳發展是不平衡的、多种多样的一 类意見䛉为: “地壳所有各个部分，都走过 同一的构造发展阶段，并且几乎同时走过”。 或者說: 在地壳发展史中，某种地槽区与 其“乎联”的某种地台区成对同时发生，又成 对同时消灭 $[1962$ ，黃 $]$ 。还有些人則把关于 地壳发展的总的历程和总的方向可以划分为 多个阶段的这个事实，理解为每个地区构造 必經的发展程序, 㪶理解为地壳的所有地段 都按着单一程序前进的。另一类意見則訓 为, 地壳各个部分的情况手不一致, 各种不 同的构造单元的出現时間固是有先有后的, 同一构造单元在不同地区的出現时間也是很 有差异的。

从地壳各个部分的大地构造发展史的差 异情况看来，可以看出，上列二类意見中， 以后一类較为正确。因为地壳发展实际上是 不本衡的、多种多样的。上面所举的已經 詳知或待詳究的各个基本发展阶段, 仅仅是 代表地壳发展的总的历程和总的方向，而不 是說它們在地壳各个不同地段都同样地走 过，更不是說它們在不同地区同时走过。苗 为实际資料表明，有些地区，例如中奥东部 大部分地区，早在古生代后期或中生代就已 經发展到地洼阶段，而另一些地区，例如傸 西北部、四川中部、松辽本原等处, 則目前 仅发展到地台阶段。更有些地区，其地稹发 
展史目前仍处在地槽阶段; 其中一部分已进 入禇铍带期(郎地槽阶段的后期)，另一部分 則甚至仍在地槽期 (郎地槽阶段的前期); 前 者如喜馬拉雅山脉，后者如太平洋西部一些 地区。再有，象太本洋底中部这样的地区， 則可能系目前还未轉入以后的各个較新发展 阶段的原始构造区阶段。師使是在原始构造 区阶段, 其发展情况也不可能是全球到处一 致的。可以假定，这个可能代表地売发展的 最初形式的构造单元, 在地球的发展过程中， 可能是各部早晚不一地开始出現，逐步扩展 而成的，又可能是各处先后不一地、逐步地 崩溃, 为以后所成的各种构造单元所代替 的。这是因为地壳各个部分內在矛盾的发展 始終是不平衡的，所以各个地段有各种不同 的經历，秚使构造发展的过程和发展阶段的 划分各有特色: 就空間上来説，同一地貭时 期內的各个不同地区，其大地构造性稹和所 在的发展阶段，可以很不相同; 郎使同一大 地构造性貭、同一发展阶段的两个地区，其 具体特点也有差异。而就时間上説，則同一 地区的各个不同发展阶段是否显著, 为期长 短, 以至是否存在, 按照先后順序的各个发 展阶段是否連續出現, 有无超越某些阶段的 現象等，都很不一致。这样，在大地构造发 展史上，由一般性与个別性的对立統一，和 連綡性与間断性的对立統一互相交織，便构 成了一幅变化复杂、丰富多彩的美妙的画 图。既然各个地区有着不同的地盾发展史， 它椚在地壳发展的总的方向和一般性規律 中，就必然各有其自己的个別性和特殊性， 并由此形成了地壳发展的多样性、任何一个 地稹时代中同时存在的构造单元的复杂性， 以及在綜合大地构造图中以目前发展阶段为 准縄(亚借此全面反映以前各个发展阶段)所
划分出来的大地构造分区的多种多样的类 型。

由此可見，那些否䚿地壳发展不平衡性 的各种災变論覌点，都是与事实不相符合 的。

\section{二 地孛发展的根本原因問題}

就地壳发展的根本原因这一問題上, 目 前的看法計有两种: 一种主张地売发展是由 于內力因素与外力因素互相斗爭的結果。另 一种則䚿为地壳发展的根本原因是由于地壳 內部的矛盾性; 外力因素只是次要的。荮先 討論地壳中各种构造单元之間在性稹上差別 的原因, 然后探索这些构造单元在性稹上发 生变化，并不断向前发展的原因問題。

\section{（一）各种构透单元性原登别的 原因間题}

1. 地壳中矛盾的普遍性，根据各种构 造单元的特征及其发展过程，我們可以看 出, 地壳当其形成之始, 郎存在着許多矛 盾。在它里面，没有不存在矛盾的地方; 在 它的发展史上，沒有不存在矛盾的时刻。例 如, 来自地球內部的放射能、重力能等产生 的热力的积聚与消散之間的矛盾, 地球物稹 主要地由于这些热能的积聚与消散所引起的

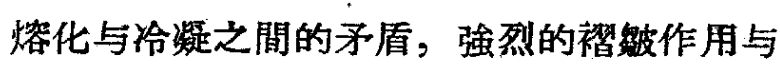
地层的被压实、变稹及硬化之間的矛盾，岩 浆侵入活动与地壳裂縫的被充填胶結之間的 矛盾，隆起运动 (离心力) 与沉降运动 (向心 力）之間的矛盾，水本应力与垂值应力之間 的矛盾，新生作用与链承作用之間的矛盾等 等。这些各种各样的矛盾中，每一对矛盾都 是互相眹系、互相依存而又互相排斥、互相 
斗爭、互相对立的; 同时，各对矛盾之間又 有联系，又有斗爭。这便构成了地壳发展的 复杂的过程。其中, 放射能、重力能等产生 的热力的积聚与消散之間的矛盾, 似系地壳 在地史发展时期中的基本矛盾。

2. 地史时期丙的主要矛盾

在上述的 各种各样的矛盾中，最主要者可以归納为两 个方面的矛盾, 郎活动因素与稳定因素之間 的矛盾。前者如放射能、重力能等所产热力 的积聚及其作用, 強烈的褶皱作用和岩浆活 动等; 后者如放射能、重力能等所产热力的 消散及該处地壳的冷凝，地层由于褶敫皮而被 压实、变稹及硬化, 地壳裂縫由于岩浆充樭 而被胶結等等。它們是在大部分的地史时期 內的主要矛盾。这两个互相对立而又互相依 存、互为条件的方面, 同时存在于地壳的統 一体中，同时存在于地壳的任何一个部分及 任何一个地貭时代。它們在地壳发展的复杂 的过程中，在不同阶段互相更替地代表新构 造单元与旧构造单元两方面的矛盾, 并互相 排斥、互相斗爭着。正如毛泽东同志所指出 的一样, “任何事物的內 部都有其新旧两个 方面的矛盾, 形成为一系列的曲折的斗争” [矛盾論]。

3. 任何构造單元里面都有主要的矛盾方 面和次要的矛盾方面 事实上, 任何一种 基本构造单元，当其在任何一个发展阶段， 里面都包含着活动与稳定这两种对立的因 素。无論是活动区还是“稳定”区，当其形成 之始，郎有它的对立因素㝋育在它里面。郎 是說, 旧构造单元中㭆育着新构造单元的因 素。新构造单元的因素和旧的构造单元一同 发生, 一同发展, 并与代表旧构造单元的因 素不断地进行斗爭, 在斗爭中逐漸成长壮大。 这样，本来占据优势地位的旧因素所代表的
旧的主要的矛盾方面, 便逐漸被制弱; 而以 新因素为代表的、本来占据劣势地位的、属 于次要的另一个矛盾方面, 則逐漸夺得优势, 終于取代了前者的支配地位, 成为新的主要 的矛盾方面。例如，地槽区为活动区，其矛 盾的主要方面为属于活动因素的强烈的放射 能等所产热力作用、櫂皱作用及岩浆活动 等。但与此同时；正是由于这些活动因素的 存在, 也就产生了由放射能等所产热力的消 散, 地层被压实、变稹、硬化, 以及裂綘由 于岩浆充填而胶結等所代表的稳定因素。这 些稳定因素随着地槽区中活动因素的发展而 逐步成长壮大。該处以前长期积聚的热能作 用愈烈, 其可供消散者師愈多; 褶铍作用愈 強, 地层被压实郎愈紧密; 岩浆活动愈盛, 地壳裂縫被胶結就忿坚固。由于这样，原居 劣势地位的稳定因素便終于取代了活动因素 的优势地位, 成为新的主要的矛盾方面。又 如, 地台区为“稳定”区, 其矛盾的主要方面 为稳定因素, 它以該处放射能等所产热力的 消散，地壳相对的冷凝、固結、硬化为代表。 但与此同时, 正是由于这些稳定因素的存在, 又㝋育了新的活动因素, 这就是放射能等所 产热力的重新积聚及其作用, 致使該处地球 物稹逐步地、不均一地再度潄化。在地台的 发展过程中, 放射能等的热力的聚积, 由少 到多, 其作用由弱到強, 这就是說, 活动因 素由小到大。最后, 活动因素便取代了原占 优势的稳定因素的主导地位，变成了矛盾的 新的主要方面，以致强烈的岩浆活动及构造 变动 (拱曲、褶皱及断裂) 等的再度出現。

4. 各种构造單元之間的性策差別是由于 矛盾的特殊性 由此可見，地壳中基本构 造单元之所以有性稹上的差別, 以及何者为 活动区，何者为“稳定”区，主要是由于它里 
面占据主导地位, 起支配作用的主要的矛盾 方面究是活动因綦还是稳定因素, 并以此表 現为矛盾的特殊性来决定的。例如，地槽区 及地洼区之所以属于活动区，是由于在它的 发展的主要时期, 以由强烈的放射能、重力 能等所产生的热力作用, 以及强烈的构造变 动和岩浆作用等所代表的活动因素占据主导 地位及起了支配作用; 而地台区之所以成为 “稳定”区，則是由于在它的发展过程中，其 矛盾的主要方面是属于稳定因素; 这些稳定, 因素是由放射能等所产热力的消散，以前所 成地层的已被強烈褶被、固結、硬化，以及 裂縫的已被岩浆充塓及胶結等所代表的。其 次，在同是活动区或同是稳定区里面，其所 以能够再細分出多种多样的类型, 也是由于 矛盾的特殊性所决定的。例如, 地槽区和地 洼区虽然同属活动区，就其主要的矛盾方面 来說，一方面有着共同的性稹，但同时又各 有其自己的特点，因而使它們二者兓互相联 系而又互相区別开来。在地槽区，其矛盾的 主要方面是地槽型活动因素; 而在地洼区， 其矛盾的主要方面則是地洼型活动因素。这 两种不同性稹的活动因素的特殊性，主要表 現在它們两者在沉积建造、构造变动、岩浆 建造、变貭作用等方面的类型上的差別 [1960，陈]。此外，它們二者在地球物理特 征上也有不同 ${ }^{[1]}$ 。

\section{（二）各种构造单元之間的性盾 化的原因}

1.构造單元轉化是地壳丙部的必然的自 已的运动 基于在地壳中各种构造单元里 面矛盾的普遍存在，以及其矛盾的特殊性对 不同构造单元性稹差別的决定作用，可以推 知, 地壳的发展, 是由于里面所包含的各种
各样的矛盾斗争，主要是活动因素和稳定因 素这两个对立面之間的矛盾斗爭，推动了它 不断前进。例如，地槽区之所以轉化为地台 区，就是由于在它里面的原属主要的矛盾方 面的活动因素 (以強烈的热能作用、构造变

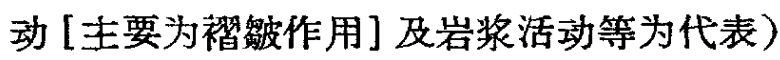
在和稳定因素 (以該处热能的消散、地层的 固結硬化及裂縫的被岩浆充填胶結等为代 表)的斗爭中，逐漸被制弱，終于为后者所代 替。同样，地台区之所以轉化为地洼区，則 是因为在它里面的原占优势地位的稳定因素 在和新的活动因素 (及以強烈的热能作用、构 造变动 [拱曲作用、褶飜作用及断裂作用]以 及岩浆活动等为代表) 的斗爭中，被后者所 克服, 日漸退居劣势, 粍訆位于后者的結 果。

总的說来，地壳在其发展的过程中，无 論它的任何一个部分，当在任何一个地貭时 代，凡是正值活动因素战胜稳定因素，夺得 优势，起了支配作用，成为矛盾的主要方面 的时期，郎表現为活动区，例如地盆区、地 槽区、地洼区等是。反之，若系正值稳定因 素战胜活动因素，夺得优势，起了支配作 用，成为矛盾的主要方面的时候，其大地构

[1] 据 A. Л. 楬申在 1960 年中苏合編欧亚大地构造图 会議上发言时的报导, 地洼区和地槽区不独在地貭 特征上有明显的差別, 而且在地球物理特征上也有 很大的不同。在地槽区,其重力算常一般为正的,或 者是正負相間的 (在地槽部分为正, 在地背斜部分为 負)。这事实,显示出这种构造区在其发展过程中,蒜 处地壳收維, 以致密度增大,并因此发生了大幅度的 沉降运动，或者至少地槽部分是如此。至于地洼区， 則其重力异常一般为負的, 不特地穹部分是如此, 就 連地洼部分也是这样。这詨明, 在这种构造区发展: 过程中,該处地壳是膨胀的, 以致紫度隇小。所以， 地洼区的总的运动方向是隆起的; 就連地洼部分也。 是如此, 只是它們对于邻側的地穹来諰, 隆起幅度較 小,致显示出相对的下降而已。这些資料,給諓們解 答了这样一个問題, 即为什么地槽型沉积建造以海. 相为主, 而地洼型沉积建造則以陆相为多。 
造性稹郎起了变化，并轉化为“稳定”区，例 如原始构造区、地原区、地台区，以及在地 洼区之后可能出現的 $Y_{1}$ 区等，均属之。地 壳的发展就是按照这个属于一切事物发展的 根本法”則进行的。地壳中活动区和“稳定”区 这两类 (注意: 不是仅仅其中特定的某两个) 对立性稹的构造单元之間的这个辯証地互相 轉化的过程, 叫做“动定轉化”。正如毛泽东 同志所閵明的一样，“矛盾着的事物依一定 的条件有同一性，因此能够共居于一个統一 体中，又能够互相轉化到相反的方面去”[矛 盾論了。

2. 对某些䙺点的討論 由此可見，地 壳的发展乃是地壳內部的必然的自己的运 动, 只有从地壳的內部去研究地壳的发展, 才能正确地找出其发展的根本原因。至于地 球和其他天体的互相联系和互相影响, 以及 其他的外部原因，虽然也有存在，但对于地 壳发展来說，只是次要的。事实說明，这些 外因如果不通过內因，郎不通过地壳內部的 矛盾性，要使一个地槽区轉化为地台区，或 要使一个地台区轉化为地洼区，看来是不可 能的。

由此又可以看出，无論由地槽区轉化为 地台区，抑或由地台区轉化为地洼区，又抑 或任何其他种类的活动区或“稳定”区向与它 自己性稹对立的另一种构造单元轉化的过 程，实稹上都是同时讲存于同一空間里面、 包含在原来的构造单元自己的內部、代表先 后不同发展阶段的新旧两个性稹对立的构造 单元的新旧因素之間的矛盾斗爭和兴亡更替 的过程 (其中新的因素且系在旧构造单元里 面㭆有出来的); 由于新旧因素斗爭的最后 結局，导致了旧构造单元被新构造单元所完
构造单元之間的对垒互攻。黄波清 [1962] 訩为: “承䚯地槽区一一地台区一一地洼区 的发展順序，实际上等于說事物的发展可以 不含矛盾”; 他还把地壳发展理解为同时并 存于不同空間的两个构造单元之間的斗爭和 轉化，并且用所謂“串联”、“升联”来比喻。 根据上交分析結果, 可以看出黃氏的覌点及 其所作的比丽，实际上否誈矛盾轉化是事物 自己的內部的运动，因而都是不正确的。

\section{三 地売发展的轉化过程問題}

\section{（一）地冢发展过程是递进演化的}

地壳无論就其整体来看，抑或就其任何 一部分来看，从一个阶段到另一个阶段，这 两个阶段之間，既各有其稹的規定性，并因 此互相区別开来，一如上述。但同时，事实 說明，它們彼此之間又有着密切的联系，不 能截然分割, 而是互相渗透, 互相过渡, 逐 步轉变的。这表現于在地壳的发展过程中, 从一个基本阶段发展到另一个基本阶段, 在 貭变的、突变的时刻之前, 显然地存在着一 个代表量变的、漸变的过渡阶段。虽然这个 过渡阶段在地壳的不同部分及不同的基本阶 段之間其长短很不一致, 明显程度也各不相 同，但其存在的事实却是无可否䚯的。例 如, 由地槽区轉化为地台区, 是通过了地槽型 的构造运动、沉积作用和岩浆活动的逐漸娍 弱，該处地壳由于經过了強烈的褶皱、变原 及岩浆凝結而逐漸“硬化”，地台区的因替遂 漸增加，最后便轉化为在性貭上与属于活动 区的地槽区显然不同的，而属于“稳定”区的 地台区。其次, 由地台区轉化为地洼区，也 往往通过了一个过渡时期，这表現在地台区 发展的后期，出現了一些“前奏活动”，郎活 
动因素逐渐增強，然后进入地洼发展的强烈 活动阶段; 或者是由局部轉化逐漸扩展为全 面轉化，地台区面积逐步減小，地洼区面积 逐漸扩大，最后才发生根本的、全面的轉 化，全部成为地洼区。例如，华北地洼区的 山西、山东、阴辽、冀辽一带, 其地洼阶段 开始或全面开始于侏罗紀，但在古生代末石 炭二迭紀时，已开始出現了“地洼一地台型 沉积”（例如山西洼隆的石盒子組及石千峯 組，阴辽注隆的栓馬椿組），或局部的地洼 沉积 (例如阴辽洼隆的薩 拉齐組)。这些沉 积, 在前一种情况为当时基本上、或大部分 还是地台型地壳运动, 但其中所孕育的地洼 型地壳运动因素是在已經显著地壮大的条件 下形成的; 而后一种情况則是在已有局部地 区形成了地洼型抅陷的环境下所沉积的。它 們都是过渡阶段的产物。这些事实，說明了 地壳的动定轉化过程是由量变到稹变, 由漸 变到突变的递进演化过程。

在同一基本发展阶段的各个不同輘小阶 段之間，也存在着濑变的、互相渗透的过渡 关系。它們彼此之間既互相区別，各有其稹 的規定性，但同时又互相交錯，紧密地联系 着。这是地壳发展由于量变的积累而成质 变，由于部分的貭变的积累而引起根本的盾 变的又一証明。例如，地槽区发展的前后两 个阶段，郎“地槽期”与“褶皱带期”之間，以 及地洼区发展的前后两个阶段，郎“地洼期” 与“褶铍带期”之間，都是不能截 然分开的 [1260, 陈]。

\section{（二）地费发展中量变与稹变的关系}

另一方面，在由量变引起稹变的地壳发 展过程中，由于貭变的結果，在新貭的基础 上, 又常引起了新的量变, 例如, 当地槽区
由于地台型地壳运动的因素逐㰾增加，最后 发生性稹上的根本变化, 轉变为地台区以 后，在地台区中及逐步开始发生了地洼型地 壳运动的因素,并且在量上逐步增加，逐漸显 著，与地台型地壳运动不断斗爭，松成了地 台区阶段的矛盾发展史。但必須指出，当一 个构造单元的性稹发生根本改变以后，其殘 余影响㪶不立師消灭。它常可出現为“継承 活动”。例如，在地台区形成初期，常可見 到代表以前地槽区阶段殘余影响的継承活 动，表現为比較強烈的构造运动、岩浆活动 或沉积作用。有时，甚至表現为反差較强的 “継承构造”，其中出現相对沉降幅度較大的 “継承台陷”。如华北地洼区翼辽洼㕷，当地 台区阶段初期，震旦紀时的大幅度下陷（造 成厚度达 9,000 米的震旦系), 郎是其例。这 一时期的特点，代表着該处元古代地槽区阶 段与古生代地台区阶段这两个基本阶段之間 的过渡阶段的延續。

\section{（三）地棠按照递进演化发展的原因}

地壳发展之所以由量变到稹变, 由穐变 到突变, 递进演化, 是因为在任何一个地稹 时代，在地壳的任何一个部分，都是既有継 承作用，也有新生作用，二者并存于地壳的 統一体中，科存于任何一种构造区里面，而 且互相斗爭着。在全部地稹发展史中, 没有 那个时代不是旧事物与新事物互相交緎着 的; 旧东西总是在衰亡，新东西总是在生 长，有死灭同时有生长正 是事物不断运动、 变化和发展过程中的必然規律。因此，不能 設想，一个地区当某一时代为地槽区，没有 任何地台型地壳运动的因素的逐渐增积而突 然軨化为地台区。由地台区轉化为地洼区也 是如此。正如恩格斯所指出的，“沒有物稹: 
或运动的增加或減少，師沒有有关的物体的 量的变化，要变化它的稹是不可能的”[ 自然 辝証法, 1959 年本, 頁 40]。

在地壳发展过程中，新旧因茎之間的矛 盾斗爭，以及它們的兴亡更替，其強烈程度 是波状起优的; 而对于介平两个基本阶段之 間的轉化时刻来說，特別尖銳，特別激烈。 因此，新旧构造单元之間的稹的变化，也就 以这些时刻为最显著。由此可見，在地壳发 展的递进演化过程中，不同基本构造单元之 間的貭的变化，乃是量的变化的积累，郎新 构造单元的因素在其与细构造单元的因素斗 爭中逐漸增多，逐漸成长壮大，而旧的构造 单元的因素則逐漸減少，漸被削弱。这是因 为每一量变都包含有部分的稹变，而局部 的、微小的稹变不断积累的結果, 最后便形 成了整体的、根本上的稹变。当新旧因素的 矛盾斗爭已經打破了旧有的統一，促使矛盾 的主要方面易位的时候，也就是新因素終于 夺得优势和支配地位，而旧因素退居劣势， 漸趋消灭，判訆位于新生力量的时候，这个 旧有的基本构造单元便发生根本的变化，轉 化为新的基本构造单元。地壳发展就是这 样, 由量变引起稹变, 积累局部的、微小的 貭变而引起全面的和根本的貭变, 通过动定 轉化，不断前进。

同样道理，由于継承作用与新生作用的 交織，逐使地台区当其形成之初，不可能完 全沒有地槽型活动的殘余影响出現; 当地洼 区形成之初，也不可能完全沒有地台型活动 的殘余影响存在。

正因为新生作用与継承作用之間的斗爭 及兴塞更替，逐致末进入任何一个新阶段之 前，常先有前奏活动; 而任何一个旧阶段結 ）束后，仍可出現継承活动。

\section{四、地壳发展的方向問題}

目前，关于地壳发展的基本方向問題， 有三种不同的兒解：第一种看法訩为地壳发 展的基本方向是直綫的，如地槽一地台說是 其代表; 主张地壳发展过程仅由泛地台区轉 化为地槽区的地台一地槽論者属之。第二种 看法訩为地壳发展的基本方向是循环的，主 张地壳发展过程是地槽区和地台区之間的普 遍可逆再生，重复出現的多輪迴諭者郎属此 說。还有第三种看法則訩为地壳发展方向是 递进的，也就是螺旋状的、向上向前的; 地 壳动定轉化递进說郎其代表。茲先討論地壳 各个不同发展阶段之間的关系，然后探索地 壳发展的基本方向。

\section{（一）地壳发展各个阶段之間的关系}

1. 地壳發展是按照“否定之否定”法則進 行的就已有的資料看来，地壳发展的各 个阶段之間，表現出“肯定一一否定”的关 系。例如，地槽区为活动区，它发展的結 果，轉化为地台区。地台区是一个“稳定” 区，是活动区的反面。这是活动区由肯定变 为否定的过程。其次，地台区及再度轉化， 成为新的活动区一一地洼区，師“稳定”区的 反面。这是“稳定”区由肯定发展成为否定的 过程。如果上溯到更古的发展阶段, 則地槽 区可能是由属于“稳定”区的地原区轉化为自 己的对立面而形成的; 这也是“稳定”区由青 定发展到否定的过程。又如考虑到地洼区的 发展前途，它将可能轉化为新的“稳定”区， 郎有待于在今后研究中注澺发見的 $Y_{1}$ 区。这 又是活动区由肯定变为否定，并轉化为自己 的对立面的过程。如此类推, 其中每一段 
“肯定一一否定”过程, 都是由两个性稹相反 的基本阶段构成的，可称为一个基本的（大 的 “动定旋呬”(指以从活动区阶段为一个旋 迴的䞨点为例而言; 如从“稳定”区阶段作起 点, 則可称为“定动旋迴”)。

从整个来看，地壳发展的过程是一个由 一系列的“肯定一一否定一一再肯定…...”所 組成的复杂过程。例如, 就目前研究比較清 楚的几个基本构造单元来説，任意从某一构 造单元, 比如从地槽区起計, 由属于活动区的 地槽区經过否定而轉变成为属于“稳定”区的 地台区，其后又由这个“稳定”区經过否定而 重成活动区一一个新的活动区，郎地洼 区，便是这个复杂的辩钲否定过程中由“肯 定一一否定一一再肯定……”許多个环节所 构成的一段。其他各个已知构造单元之間的 祓証否定关系，也是如此。这个讋証否定关 系，也就是通常所称的“否定之否定”的关 系。

2. 地壳按照“否定之否定”法則弡展的 原因地壳发展之所以按照“肯定一一否 定一一再肯定”，郎“否定之否定”的关系进 行，其根本原因是由于一切构造单元其內部 都包含着肯定与否定这两种对立的因素, 以 及由此形成的一系列曲折的斗爭，推动着各 个构造单元都由肯定发展为否定。任何一个 构造单元，其开始是在它的肯定阶段，但它 的內部同时孕育着否定自己的因素, 師前面 所迅的旧构造单元中孕育着新构造单元的因 莱。，例如，对于地槽区来說，它开始处于活 动区性质的阶段。其时在它里面占据主导地 位的、以強烈的热力作用、習解作用、岩浆 作用等为代表的活动因素，便是肯定的因 素。它們决定了这个构造单元还处在肯定阶 段。但正是由于这些肯定因素的存在和发
展，又产生了否定自己的因素，郎前述的、 以热能的消散、地层的被压实、地壳裂綘的 被胶結等为代表的稳定因素。这就为地槽区 否定自己創造条件。这些否定因素便是地台 因素。他們起初只居次要地位, 在和肯定因 素郎地槽因素不断斗爭中，經过曲折的道路 (表現为 “稳定” 特征的时显时隐)，由小变 大，从某些局部上直到整个构造单元的全体 上逐步地夺得矛盾的主要方面的地位。与此 同时，肯定因素郎地槽因素方面，經过反复 的㧺扎（表現为活动強度的波状起伏及延續 运动); 由大变小, 而逐步地归于衰亡。当 肯定因素还占主导地位的时候，作为旧的构 造单元的地槽区，其发展还在量变阶段，还 未发生显著的盾变。但到这时，就完成了量 变过程, 由局部的貭变、局部的否定达到根 本的稹变、根本的否定。于是地槽区就由肯 定发展到否定，轉化为地台区。他如地台区 向地洼区发展, 是由于在这一发展阶段內, 代 表肯定因素郎稳定因素(地台因素)，与代表 否定因素郎另一类型的活动因素(地洼因素) 的矛盾两方經过一系列曲折斗爭，由肯定发 展为否定的結果。在地台的发展过程中, 否 定因素郎活动因素由于放射能、重力能等所 产热力的重新积聚結果，逐漸成长壮大，迫 使原占优势及主要地位的肯定因素郎地台因 素，退居劣势及次要地位，終于否定了地台 区而轉化为地洼区。所以，一种构造单元由 肯定发展为否定，乃是它的內部矛盾发展的 必然結果。各种构造单元都是在一定条件与 环境下自己否定自己的。所以, 这是自身的 否定。

任何一种构造单元的自身的否定, 实稹 上是矛盾的对立面的轉化, 是旧稹的死亡与 新稹的产生。每一次的否定, 总是新稹战胜 
旧稹。旧的构造单元被新的构造单元所否 定，新的构造单元又被更新的构造单元所否 定。这样便形成了一个新陈代謝的复杂的地 史发展过程。正如毛泽东同志已經䦭明的一 样, “一切过程都有始有終，一切过程都轉化 为它們的对立物。一切过程的常住性是相对 的, 但是一种过程轉化为他种过程的这种变 动性則是絕对的”[矛盾諭]。地壳发展的“否 定之否定”过程，正是这样不断地由一种性 质的构造单元轉化为与它对立性稹的他种构 造单元，不断前进的动定轉化过程。黃汲清 [1962]之所以把地壳构造的矛盾轉化理解为 并存于不同空間(他所謂“銿联”)的二个构造 单元之間的斗爭，而否訩为同一空間的前后 两个阶段的新旧(他所謂“串联”)的构造单元 之間的斗学(見上交)，其錯誤的主要原因郎 系由于他不承訓矛盾轉化实系事物自身的否 定这个基本原理所致。黃氏还枉費心机地說 地注区没有对立物，并以此作为否定它存在 的主要理由，其实这問題是十分簡单的，只 要运用“否定之否定”法則进行分析, 就可以 找到答案：地洼区既是活动区的一种，它的

\section{- 对立物当然是那些与它有直接的历史生因关} 系的“稳定”区。一般地說，一方面，当它还 在較老的“稳定” 区里面孕育和成长的时期， 它的主要斗爭对象就是作为它的前身的地台 区; 另一方面, 当它形成以后，新的“稳定” 区的因素在它里面孕育和成长的时期，它的 圭要斗爭对象就是将为它的后身的 $Y_{1}$ 区(在 地洼发展初期, 还有地台因素的殘余, 但此 时已降为次要的斗爭对象了)。

\section{3. 地壳發展过程中肯定与否定的关系} 地壳发展的肯定和否定是統一的, 不独肯定 的过程中包含有否定的因素, 就是在否定的 过程中也肯定旧构造单元的某些东西，作为
自己的組成部分而継承下来。而且，事实說 明, “无古不成今”，継承是新构造单元发展 的必要条件。但必須指出, 新构造单元在否 定旧构造单元的时候, 已从根本上改变了、 克服了旧构造单元的性稹, 所肯定及継承的 仅仅是旧构造单元中的某些組成部分。例如 由地槽区向地台区轉化过程中，作为新构造 单元的地台区，改变了及克服了旧构造单元 地槽区的属于活动区的性稹，轉化为“稳定” 区。但与此同时，地台区又継承了它的前身 由地槽禇解带的殘留 部分所組成的构造层 （并借此間接継承了前地槽区阶段的各个更 古的构造单元殘留部分所組成的其他构造 层)，作为自己的褶橎基底 (及結晶基底)。 地台区自己特有的构造层 (地台构造层或称 沉积盖层) 郎以此为条件和基础，科在其上 发展起来。再如, 地洼区在否定地台区的时 候，已从根本上改变了、克服了地台区的“稳 定”区性稹，轉化为一个新的活动区。但与 此同时，地洼区的发展，是以継承地台区的 殘留部分所組成的构造层（并借此間接継承 前地台区的各个更古构造单元的殘留部分所 組成的其他构造层），作为自己的基础，并 以此为必要条件的。地洼区自己特有的构造 层 (地洼构造层) 郎系在这些基础之上发有 而成的。

\section{（二）地冢发展的㟟本方向}

1. 地壳墢展的基本方向是魀迭升進的 从各种构造单元之間的区別和联系来看, 地 史发展就其基本方向来說, 是不重复的。在 地壳的不断的、以动定轉化 (郎活动区与“稳. 定”区这两类性稹不同的构造单元之間讋証 地互相轉化)、剙因此构成多个大的动定旋 迴为标志的“肯定一一否定——再否定…...” 
过程中, 新成的构造单元,一般說来, 半不是 該处以前有过的构造单元的再度出現。茲以 “地槽区一一地台区一一地洼区”这一段环节 为例，其中的地橝区和地洼区二者在地稹发 展的否定之否定过程中，对于地台区这个否 定环节来說，是肯定和再肯定的关系，它們 二者同作为地台区这个“稳定”区的对立面而 出現的，因此都是活动区性稹的构造单元， 二者之間在某些特征上和发展过程上且有些 相似。然而这两个先后不同发展阶段的活动 区，并非相同的一种构造单元; 它們虽有其 质的共同性，但显然也各有其稹的特殊性。 地洼区无論在地稹特征上 (包括結构、沉积 建造、构造类型、岩将建造、变稹类型等) 抑或地球物理、地球化学的特征上, 都和地 槽区有明显的差別。所以地注区不能被䚯为 是該处过去已經有过的地槽区阶段的簡单重 复(郎所謂“再生”); 它一方面由于与地槽区 的稹的共同性而体現出事物发展的曲綫性和 类似重复性, 但另一方面又通过它的稹的特 殊性而反映出事物发展中的前进性，以及克 服与粎承的关系; 它虽然在发展过程中再現 了地槽区的某些类似的特征, 但这只是在更 高基础上的再現，而并不是回到出发点的复 归。地洼区的全部特征表明，它是这样的一 种基本构造单元: 它一方面再現了以前地槽 阶段的属于活动区的性稹, 链了实了它的某些 特点，但另一方面又增添了許多新的特征, 形成了另一种活动区的类型; 同时，它在結 构上表現出比无論地槽区抑地台区都更为复 杂的形式, 在地壳发展史上代表更为高級阶 段的产物。同样，地台区对于前地槽区阶段 中所已出現过的、属于較老发展阶段的“稳 定”区 (例如地原区) 来說，以及地槽区和前 地槽区阶段所已出現过的、属于更老发展阶
段的活动区（例如地盆区）相比較，在性稹 上、特征上和发展过程上虽然也各有其相似 之点, 但也都不是相同的一种构造单元。新 的构造单元不能被訓为旧有构造单元的簡单 重复或所謂“再生”，而实系各自代表較高发 展阶段的产物，因而也就有必要給予不同的 名称，而不应混清地一律称为地槽区或地台 区; 那些仅在槽、台之前加上萌、刎、原之 类的名称，也是不能正确反映其实稹的。

根据上交分析結果，地壳发展的总的过 程, 乃是螺旋状、波浪式、“之”字形地不断向 上向前发展的递迭升进的过程（图 2)。这

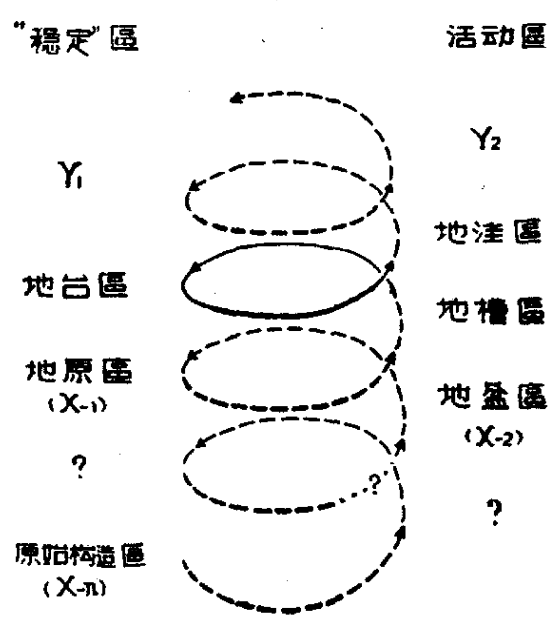

\section{图 2 地究发展規律示虫图}

个过程，就其基本方向来說，是前进上升 的，但具体的道路又是曲折的。这体現出事 物內部矛盾发展变化的規律。試从地壳发展 的一連串的环节中任何一个环节来看, 开始 由肯定发展为否定, 否定再发展为再肯定。 这样經过連續的否定, 就在較高級的基础上 仿佛(但不是真的)回到原来的出发点, 完成 了一段发展过程。从这个新的起点出发, 又 进入新的一段发展过程。这样，經过了多个 連續的否定，便形成了“肯定一一否定一 再肯定……”的过程，出現了許多个大的发 展阶段; 由許多个活动区阶段与“稳定”区阶 
段相間連接，便构成了許多个大的动定旋 迴。由于新旧构造单元之間，肯定和否定 的每一次轉化，都进到了更为高級的阶段。 因此，这个过程的总趋向是由低級阶段发展 到高級阶段的。同时，由于当新构造单元否 定旧构造单元的时候，不但克服了以前阶段 的性稹，粎承了以前各个构造层的殘留部 分，而且还增添了自己特有的新的构造层。 所以，每一个新的构造单元一般地說都比原 来的构造单元具有更为复杂的結构。这样, 这个过程的总趋向及是由簡单发展到复杂 的。这些事实, 都足以証明地壳发展中的动 定轉化，从它的总的趋向来看：是一个前进 上升的运动，故曰“递进”; 我們所称的 “地 壳动定轉化递进律”，郎系指此。

地壳发展的波浪式、“之”字形曲折前进 的动定轉化递进規律，不仅表現在其发展过 程中的不同基本阶段之間，而且表現在同一 基本阶段里面的輘小阶段之間新旧构造因素 的斗爭上。例如，由地槽区轉化为地台区的 过程中，代表活动因素的地槽型地壳运动特 征，其总的趋向是逐漸減弱，退居劣势，但

6 仍然时有再度增強, 起伏地前进的事实。这 就表現为地槽区发展后期的“延續运动”; 中 国穓內的䄮連、菨耑等地槽区所見，郎其代 表。这两个地槽区原系于古生代結束了地槽 期，先后形成替留殷带，但在中生代及新生代 两度出現强烈活动，再度升起。又如在地台 区发展初期，代表稳定因素的地台型地壳运 动特征，其总的趋势是越来越显著，靽且已 經占居优势，但仍然起伏地有时出現了地槽 型地壳运动殘余的較強的活动，代表过渡阶 段的延續; 前述华北地洼区的古地台阶段初 期，震旦紀时，在冀辽洼陷所出現的、代表 元古代地槽区殘余活动的強烈的“継承活动”
(表現为“継承台陷”)，郎其一例。再有，在 地洼区发展过程中，由初动期到剧烈期，以 及由剧烈期轉入余动期, 也是一起一伏地前 进的 $[1960$, 陈]。以上这些事实，証明旧 的构造单元并不是自动退出地史舞台的，而 是經过反复的㳟扎走向灭亡的; 同时也証 明，新的构造单元并不是一帆风順地成长 的，而是在与旧的构造单元反复斗爭中，通 过曲折的道路才取得胜利，并終于取得胜利 的。毛泽东同志指出：任何新生事物的成长 都是要經过艰难曲折的斗爭。地壳发展的規 律, 正是如此。

由于地壳发展从一种构造单元轉化为另 一种构造单元，是由量变到稹变的过程，是 由相对稳定到急剧变化(飞跃)的过程，而在 相对稳定的量变过程中还包含着部分的稹 变，这就是說，有着小的、部分的否定。所 以在复杂的、长期的地壳发展的大的“之”字 形曲折过程中，在大的波浪式的发展阶段和 大的动定旋迴里面，还包含着小的起伏，小 的波浪，玤因此形成了小的发展阶段和小的 动定旋迴，按照小的“之”字形曲折前进。

2. 地壳發展的可逆性問題还应附带 指出，地壳发展是沿着“肯定一一否定一 再肯定…...”的曲折道路前进上升的动定轉 化递进的，其不可逆性是不容否䚯的。虽 然, 有时也有一些例外情况的报导, 師在地 槽区轉化为地台区这样的不可逆发展的总的 趋向中，据說有在地台之上再度发育地槽的 現象。关于这問題，有六种可能性，視不同 地区的具体情况而定：（1）地台之上确实发 生了地槽。这是应首先考虑的, 但同时还有 其他的可能性也是値得注意的。例如: (2) 所 指的地槽, 可能实系地洼, 如頓巴斯盆地是。 （3）所指为地台者, 其由結晶基底所代表的 
构造层, 可能实为地原构造层或地盆构造 层，而不是地台构造层。如許多地槽区的地 槽构造层之下所見的結晶基底是。（4）所举 出的地槽沉积之下存在着所謂“地台型沉积” 者, 可能实系地背斜上或中間地块上的“类地 台沉积”[1960,哈], 又或系地槽发展过程中 “休眠时期”所成的“类地台沉积”，如华南地 洼区浙桂洼陷湘南一带介于元古代地槽沉积 (板溪)与加里东地槽沉积“龙山莘”之間的 震旦寒武系是。（5）地台阶段发展初期, 在 局部地区由于受以前地槽阶段殘余影响較著 的过渡阶段的延續，发生了“継承台陷”，代 表継承活动的产物，如华北地洼区翼辽洼陷 內的震旦紀古台陷是。（6）地槽区与地台区 交界处的过渡地带, 由于双方的互相影响,地 槽型沉积与地台型沉积互相交錯，以致地槽 型沉积可以掩盖在地台型沉积之上。上述六 种可能性中，无論何者是实际情况，就現有 資料看来，确属最前一种可能性所表現的逆 轉情况, 䋱有存在, 一般地説, 不过是次要 的、局部性稹的。这已由 H. И. 尼古拉耶夫 [1955，尼]論述过了。我們承訜地壳发展有 其統一性及一般規律性，半不意味着、也不 能理解为否䚿地壳发展的多样性、地壳各部 分的个別性和特殊性，以至某些地区所出現 的例外情况。反过来, 我們師使确实发現了 在压倒优势的由地槽区轉化为地台区的总的 过程和基本方向中，可能有某些局部性的逆 轉現象的存在, 并不能用来作为否訓地壳发 展的总的方向是前进上升这个一般規律性的 根据。更不能据此得出結諭, 䚲为地壳发展 的一般規律就是槽台可逆循环 (郎訩为地槽 区与地台区之間的一般关紊是所謂 “可逆” 的）。采用历史法分析了黃波清 [1962] 所举 出的那些大多数属于似是而非的所謂 “可逆
再生” 的“例子”, 可以看出, 他䚯为所謂地台 “再生”重成地槽的可逆現象是普遍性的团团 轉的多輪迴覌点，显然是不符合客覌实际的， 同时也是违反“否定之否定”法則的。如上所 述，动定轉化递进律指的是活动区和“稳定” 区这两类不同性稹的构造单元之間的就証地 互相轉化，不断升进; 这不能理解为地槽 区与地台区这两个特定的构造单元之間的可 逆再生，循环不前。

3.地壳發展中的超越階段問題此 外, 在按照否定之否定法則, 通过动定轉 化、递迭升进的地壳发展的总的历程中，有 时出現了超越或似乎超越某些阶段的現象。 例如，在代表前地槽区阶段（如地盆区阶段 或地原区阶段）的古老构造层（結晶基底）之 上直接超复着地台构造层, 有时甚至直接超: 复着地洼构造层。如华北地洼区的阴辽洼 隆、山东洼隆等处的部分地区，曾經見之。 又有时，代表地槽区阶段的褶秛基底 (地槽 构造层) 之上，沒有代表地台区阶段的地台 构造层发育而直接出現了地洼构造层, 如东 北地洼区所見，郎其一例，这也是超越或似 乎超越某些阶段的現象。这些現象体現出地 壳发展的一般規律性与个別性的对立統一, 以及統一性与多样性的对立統一。虽然, 地 壳发展的各个不同阶段在不同地区其长短是 很不一致的, 有时一个基本发展阶段比較短 促, 就会使其前后两个其他基本发展阶段看 起来好象舒接一起。其次, 代表某一基本发 展阶段的构造层的缺失, 也有可能是由于当 时没有沉积, 或者虽有沉积但因后来的剥蝕 作用而失去, 而不一定是該发展阶段沒有存 在的証明。这些都是应該考虑到的。另一方 面, 还要指出, 在地壳发展过程中，尽管有 时出現了超越某些阶段的現象, 就現有資料 
看来，不过是次要的、局部性稹的。地壳发 展的基本方向及一般規律，仍然是邀循着否 定之否定法則的动定轉化。

\section{五結語}

总結上述各点, 可以看出, 地壳发展就 是嗱循着“不断发展与发展阶段对立統一”这 个事物发展的普遍規律，多构造单元和多阶 段地, 以及多样性地和不本衡地, 由于內部 存在的活动因素和稳定因素这两个对立面之 間的矛盾斗爭，从量变到盾变，从漸变到突 变, 从簡单形式向复杂形式发展, 从低級阶 段向高級阶段发展; 掦弃旧的，形成新的， 按照螺旋状上升的基本方向，通过动定轉 化，不可逆地从一个动定旋迴到另一个动定 旋迥，递迭升进。

主张地槽一地台說的学者根据自己对地 壳发展規律的訩識，以为地壳发展初期，整 个地球到处的活动性都是非常強烈的; 而自 太古代以后，地球的构造作用力已漸消失。 于是他們由此得出所謂整个地球构造活动性

‥已經消失或郎将消失的假定。从地壳发展的 动定轉化递进这个一般性規律看来，地壳发 展过程并非如此簡单地、直綫地和齐一地仅 仅由活动趋于靜止,而实际上是一个复杂的、 波浪式地和多样性地不断前进的过程。它过 去曾在不同时期不同地段多次地但不一致地 有过強烈活动阶段和相对稳定阶段，升多次 地但不一致地形成了各种各样的活动区和 “稳定”区，而在今后一个很长的地貭时間
內，这种波浪式发展想必仍将継續。地球的 发展还有长远的前景; 人类有着敒久的、无 限美好的共产主义的未来!

按照各个已知的构造单元的历史生因順 序, 以动定轉化、递迭升进为标志的, 循着 螺旋式路綫的地壳构造发展的总的历程和基 本方向，可用一簡式示澺如下:
原始构造区 $\rightarrow \cdots \rightarrow$ 地盆区 (?) $\rightarrow$ 地原区 (?) $\left(\mathrm{X}_{-n}\right)$ $\left(\mathrm{X}_{-2}\right)$ $\left(\mathrm{X}_{-1}\right)$

$\rightarrow$ 地槽区 $\rightarrow$ 地台区 $\rightarrow$ 地洼区 $\rightarrow Y_{1} \rightarrow \cdots \cdots$ 。

[1] 恩格斯: 自然辯証法, 1925。

[2] 毛泽东: 矛盾論,毛泽东选集第一告, 頁 287-326。

[3] 列宁: 談辯証法問題, 列宁全集, 1941 年本。

[4] H. И. 尼古拉耶夫: 关于地槽說的几个問題, 地 盾专咕 9 号，地盾出版社，1955。

[5] 陈国达: 地壳动定轉化递进說, 地盾学报 39 (3), 1959。

[6] H. И. 尼古拉耶夫: 关于研究中国新构違的若下 理論与方法問題, 科学出版塥, 1959 。

[7] 陈国达: 地台活化說及其 找矿意义, 地盾出版社, 1960。

[8]陈国达：地洼区的特征和性盾及其与所謂“准地台” 的比較, 地稹学报 $40(2), 1960$ 。

[9] 陈国达: 关于划分构造区的一些覌点和思相方法間 題, 科学通报, 1960 , 第 17 期。

[10] B. E. 哈因及 Ю. M. 謝音曼：地槽学訜一百年，苏 联地盾学杂志, 1960 (11)。

[11] 陈国达: 关于先震 旦紀地壳发展史的初步看法, 1961 。

[12] 許善明：論“准地台”及“多輪迴”的实盾,科学通报, 1961,9 月号。

[13] 莫柱孙: 广东省区域地貭构造特征及其有关大地构 造发展的几个問題, 广东地稹通訊，第 6 期，广东 地盾局地稹呼究所。

[14] 黃汲清: 从多輪迴构造运动覌点初步探討地壳发展 規律，地貭学报 $42(2), 1962$ 。

[15] 陈国达、陈恩民: 大地构造学, 中南矿治学院謰义 室及中山大学出版科, 1962。

[16] 莫柱孙: 两广地区中生代以来的断裂变盾作用, 中 国地稹学会 1962 年年会論交。 